\title{
A PROTEÇÃO À NATURALIDADE DO PATRIMÔNIO GENÉTICO FACE À PROPOSTA DA EUGENIA LIBERAL: O FUTURO DA NATUREZA HUMANA EM JÜRGEN HABERMAS
}

\section{Ana Thereza Meirelles Araújo ${ }^{1}$}

Resumo: Artigo destinado à reflexão das consequências decorrentes do acesso à informação genética a partir do entendimento de Jürgen Habermas. Análise da intervenção no processo de constituição natural da vida e da necessária garantia de continuidade da proteção do patrimônio genético. Busca-se identificar a medida de justificação das intervenções diagnósticas que evidenciam uma eugenia de natureza liberal com finalidades distintas: terapia e aperfeiçoamento. Aborda-se, a partir do caminho metodológico dedutivo, o problema da ausente demarcação de limites que conformam a eugenia em sua forma negativa e em sua forma positiva.

Palavras-chave: eugenia liberal; neoeugenia; patrimônio genético; natureza humana; autocompreensão da espécie.

\section{THE PROTECTION OF THE NATURALITY OF GENETIC HERITAGE TO THE PROPOSAL OF THE LIBERAL EUGENICS: THE FUTURE OF HUMAN NATURE IN JÜRGEN HABERMAS}

\begin{abstract}
Article intended to reflect the consequences of access to genetic information from the understanding of Jürgen Habermas. Analysis of the intervention in the process of natural constitution of the life and of the necessary guarantee of continuity of the protection of the genetic patrimony. It seeks to identify the measure of justification of diagnostic interventions that evidence a eugenics of a liberal nature with different purposes: therapy and improvement. From the deductive methodological approach, the problem of the absence of demarcation of boundaries that shape eugenics in its negative form and in its positive form is approached.
\end{abstract}

Keywords: liberal eugenics; new eugenics; genetic heritage; human nature; selfunderstanding of the species.

\footnotetext{
${ }^{1}$ Doutora em Relações Sociais e Novos Direitos pela Universidade Federal da Bahia (UFBA). Mestre em Direito Privado e Econômico pela Universidade Federal da Bahia (UFBA). Professora das disciplinas Biodireito, Bioética, Direito Civil e Metodologia da Pesquisa Jurídica da Universidade Católica do Salvador (UCSal), da Universidade do Estado da Bahia (UNEB) e da Faculdade Baiana de Direito. Contato: anatherezameirelles@gmail.com.
} 


\section{INTRODUÇÃO}

O acesso à informação genética descortinou um plexo de questões éticas e jurídicas atinentes à forma com que se compreendeu até então a constituição e o surgimento da vida humana. O desvelamento do conteúdo do DNA passou a possibilitar a resignificação da perspectiva médico-preditiva na medida em que passou-se a ser possível lidar com a efetivação do direito à saúde por meio do viés preventivo.

O problema é que a questão não permanece cingida à finalidade terapêutica ou preditiva. O acesso à informação genética propicia a ultrapassagem do limite terapêutico, aprioristicamente acordado como um benefício real, para aportar-se numa análise de cunho aperfeiçoador. A possibilidade então é que as manipulações biológicas sobre as células humanas reprodutivas também se concretizem a partir de uma motivação fundamentada pela ideia de melhoramento, de perfeição genética ou de busca por determinados padrões fenotípicos que naturalmente podem servir de alicerces a ideias racistas, preconceituosos e segregacionistas.

Habermas aprecia o binômio terapia versus aperfeiçoamento a partir da sua principal consequência: a modificação da forma com o ser humano se autocompreendeu ao longo da história de sua existência.

O objetivo proposto então é justamente avaliar a relação entre o argumento de cunho benéfico, que tenta justificar as intervenções biológicas, e a consequência principal dessa intervenção, que é a mudança na forma de autocompreensão da espécie.

A ausente demarcação do limite que separa a perspectiva terapêutica da perspectiva aperfeiçoadora motiva a investigação das respectivas diferenças posto envolver a desconstituição natural do patrimônio genético. Propõe-se analisar o espectro identificado por Habermas a partir do conhecimento científico que justifica a admissibilidade das escolhas seletivas, chamadas atualmente de neoeugênicas, pautada em motivações preditivas. A neoeugenia, também chamada de eugenia liberal, opera-se pelo convencimento de que a sua proposta é puramente benéfica, mas não encara as consequências decorrentes da ausente demarcação entre o deva restar proibido e o que deva de fato ser permitido.

A proposta tem como abordagem metodológica o caminho hipotético-dedutivo por partir da construção de interpretações concernentes ao direito vigente e a argumentos de outros segmentos científicos e filosóficos, que apontarão por dedução as perspectivas 
conclusivas em conformidade ao problema levantado. Espera-se, por meio desta perspectiva metodológica, alcançar o esclarecimento necessário ao impasse delineado.

\section{O FUTURO DA NATUREZA HUMANA E O CAMINHO PARA A EUGENIA LIBERAL}

A capacidade de manipular a si próprio, interferindo na conformação natural da própria espécie, tornou-se uma realidade promissora, mas, ao mesmo tempo, obscura por ser capaz de demandar transformação significativa na forma de autocompreensão do ser humano, concernente aos aspectos relacionados à sua existência biológica, psicológica e espiritual. Habermas (2010) sintetiza a prevista revolução advinda da biotecnologia, associada aos conhecimentos da medicina reprodutiva e da genética, que transforma e continuará a transformar a forma com que até então se estabaleceu a compreensão sobre a existência da nossa própria espécie. O Futuro da Natureza Humana: A caminho de uma Eugenia liberal? é a expressiva demonstração da complexidade dos questionamentos éticos contemporâneos que circundam os problemas decorrentes do acesso à informação genética através das manipulações biológicas.

Os avanços da medicina genômica ameaçam a construção e o desenvolvimento de um ser humano livre e autônomo e a potencialidade da informação e da capacidade manipulatória do genoma humano é capaz de desconstituir a concepção que a humanidade tem sobre si própria, seja no espectro coletivo ou contigenciado pela ótica individual.

As descobertas genéticas fomentam o medo da eclosão de pretensões eugênicas, muitas vezes, mascaradas pela escalada biotecnológica que almeja convencer o imaginário social que tais possibilidades são exclusivamente beneficentes. A desfronteirização entre a naturalidade e a artificialidade desvela a potencial tarefa da biotecnologia e descortina o repensar em torno da compreensão humana sobre si mesmo (MEIRELLES, 2014).

O inegável plexo de benefícios médicos, originado pela possibilidade de acessar o conteúdo do DNA, se opõe aos receios decorrentes da administração dos fatos desconhecidos. O uso da informação genética ainda hoje parece distante ao corriqueirismo das vidas em geral, mas, amanhã, conforme a perspectiva da narrativa de Habermas (2010), será uma realidade globalizada, acessível e inevitável à constituição das vidas humanas. A Genética, na sua concepção médica predominante, é o instrumento descortinador das informações necessárias à 
sobrevivência e à longevidade da espécie.

A análise habermasiana transforma o convincente argumento puramente beneficente em extrema dúvida, ao revelar que, agora, o ser humano passará a ser demandado a repensar a forma com que se compreendeu historicamente. A tradição da concepção humana em torno de si mesmo passa a ser rechaçada na medida em que o elemento artificial agrega uma nova realidade. A possibilidade de manipular a si próprio é o elemento de transformação das convicções naturais, pois o ser humano, hoje, pode passar a não ser fruto de um acaso genético, encontro natural entre gametas de pessoas que praticaram conjunção carnal e geraram uma outra pessoa geneticamente imprevisível, mas, sim, de um projeto parental programado que busca, por meio da seleção genética, um resultado previsível (MEIRELLES, 2014).

As manipulações biológicas seletivas em torno do genoma evidenciam a classificação das novas formas eugênicas: a eugenia negativa, que aparentemente pode ser justificada pelo argumento terapêutico, e a eugenia positiva, incialmente considerada injustificada. O limite entre as duas é flutuante e portanto a contenção de intervenções que tangenciam a margem do aperfeiçoamento genético carece de fronteiras precisas. O não reconhecimento de um limite entre as intervenções terapêuticas e as intervenções de aperfeiçoamento já é um argumento que serve à defesa de uma eugenia liberal, que admite as preferências individuais dos integrantes do mercado no processo de escolha das características do futuro filho (HABERMAS, 2010, p.26-27).

\section{OS PROBLEMAS DECORRENTES DA PROPOSTA NEOEUGÊNICA E A NECESSÁRIA PRESERVAÇÃO DA NATURALIDADE DO PATRIMÕNIO GENÉTICO}

$\mathrm{O}$ acesso à informação genética no final dos anos 60 e no início dos anos 70 evidenciou o crescimento das práticas seletivas (ou de eugenia) com objetivo terapêutico conduzidas pelo enorme potencial das técnicas de diagnóstico genético. A ascensão de algumas áreas da medicina, como a embriologia, a genética molecular e a bioquímica culminou no aperfeiçoamento dos métodos de reprodução humana laboratoriais, como a fecundação in vitro. A questão é que, paralela à ascensão da eugenia motivada por indicadores terapêuticos, surgiu também a possibilidade de manipular o DNA humano com objetivos de aperfeiçoamento ou melhora da espécie. 
O estágio atual das possibilidades de prática de escolhas seletivas de natureza eugênica aponta para o binômio terapia $x$ aperfeiçoamento. No entanto, a linha tênue entre o que pode ser uma conduta motivada terapeuticamente e o que pode ser considerada uma conduta de motivação aperfeiçoadora traduz a difícil demarcação conceitual de cada uma delas. A dificuldade de demarcação entre as duas perspectivas é a evidência do caráter complexo da discussão, inclusive, porque a questão preliminar está em identificar o que de fato se deva compreender como motivação de ordem terapêutica. A extensão dos comprometimentos que podem acometer a saúde ou o desenvolvimento normal de um ser humano perpassa pelos diferentes estados de gravidade que a patologia identificada pode agregar.

A eugenia tradicionalmente conhecida pela sociedade é rechaçada pela expressiva maioria dos seres humanos. A revolução ocasionada pelo acesso aos novos conhecimentos genéticos, biotecnológicos e moleculares desparametrizou a concepção predominante de eugenia, dando-lhe um refinamento doravante inexistente justificado pela incidência de características sedutoras. A nova eugenia então se apresenta como significativo benefício à espécie humana, já que somente se consubstancia em sede de vida humana preliminar, e agrega motivação facilmente convincente, balizada pelo ideal de persecução do afastamento de patologias diagnosticadas e da melhoria da qualidade da vida.

Essa nova forma de praticar escolhas seletivas em sede de vida inicial, denominada por Habermas de eugenia liberal, tem como pressuposto almejar o aperfeiçoamento (ou melhoramento) da espécie a partir de uma lógica ditada pelo mercado que se concretiza por meio do atendimento às demandas individuais que evidenciam preferências e preterições. A eugenia liberal é conformada a partir da lógica dos escolhidos e dos preteridos, quando analisado o impacto de tal perspectiva na dinâmica das relações sociais.

Essa nova conformação da eugenia, motivada por mudanças sociais e novas demandas de mercado, reveladoras de vontades individuais, movidas por padrões de preferência, também pode ser chamada de neoeugenia (CASABONA, 1999). Assim, é processada a concretização de desejos advindos do atual estágio do desenvolvimento científico e descortinada uma realidade de riscos não claramente conhecidos, tendo em vista a complexidade do conhecimento biotecnológico, já que não é possível identificar com clareza quais são as imediatas consequências da prática de tais intervenções (BECK, 1998).

Acrecente-se que a fusão das descobertas sobre o genoma humano ao avanço das 
técnicas sobre reprodução assistida abriu novas possibilidades à concretização do pensamento eugênico. $\mathrm{O}$ valor preventivo das análises genéticas em torno do processo de reprodução é o fator responsável por tal abertura. Aconselhamentos genéticos, diagnósticos em gametas, embriões e fetos e a engenharia genética são as técnicas novas que fizeram ressurgir a admissibilidade do pensamento eugênico, traduzido, como neoeugenia ou eugenia liberal (CASABONA, 1999).

As práticas eugênicas passadas se comunicam às práticas neoeugênicas porque ambas possuem a proposta seletiva como finalidade. A afinidade está nos objetivos, a diferença é perceptível a partir da forma com que se concretizam e do contexto em que são praticadas. A prática da neoeugenia pressupõe a obtenção do consentimento dos seres humanos nascidos, envolvidos no projeto parental almejado, elemento descartado em épocas predecessoras. A mudança está no caminho e na forma intervencionista para a obtenção de um mesmo resultado, motivado por uma mesma perspectiva, que é efetivar padrões de escolha. Assim, pode-se pensar que as perspectivas estão unidas pela finalidade, mas se concretizam de maneiras distintas.

Compreender a nova eugenia como uma questão médica situada apenas na esfera da relação médico-paciente é uma questão fácil, o que sugere se tratar de situação apenas pertencente à esfera da natureza privada.

O engano está no fato de que, além dos envolvidos no projeto parental programado, a possibilidade intervencionista atinge a constituição natural das gerações futuras e, consequentemente, a integridade e a diversidade do patrimônio genético. Nos sistemas democráticos, a nova eugenia pode ser confundida com as prerrogativas relacionadas ao exercício dos direitos individuais. A partir dessa confusão, alguns autores apontam para o fato de que passa-se a questionar se essa nova forma de seleção deve ser qualificada como uma nova forma eugênica já que está alicerçada em direitos de reprodução (CASABONA, 1999, p.11). O delineamento de tais escolhas pinta um panorama diferente, na medida em que não descarta o consentimento dos genitores para consecusão do projeto seletivo, fator que pode tornar convincente a legitimidade das práticas.

As manipulações biológicas sobre o material genético humano desembocam numa gama expressiva de condutas que podem agregar coeficientes seletivos e podem se manifestar através de técnicas diferentes, conforme classificação que segue:

Diagnóstico preconceptivo: tras las pruebas correspondientes, el médico presta información a una pareja o persona individualmente, antes del 
embarazo, sobre los riesgos de concebir un hijo con enfermedades o anomalías genéticas, hereditarias o cromosómicas.

Diagnóstico preimplantacional o preimplantatorio $(D G P)$ : se trata de detectar las posibles anomalías cromosómicas o alteraciones genéticas que pudieran tener los embriones "in Vitro" antes de ser transferidos al útero materno.

Diagnóstico prenatal: supone la realización de técnicas encaminadas a investigar la existencia o no de anomalías, malformaciones y enfermedades hereditarias o genéticas del feto.

Diagnóstico postnatal: sometimiento a pruebas de un recién nacido para detectar la posible anomalía o enfermedad que pueda presentar, o su predisposición hacia un desorden concreto (EMALDI CIRIÓN, 2001, p.14).

O diagnóstico pré-conceptivo ou aconselhamento genético para fins de planejamento reprodutivo tem a finalidade de averiguar a probabilidade de manifestação de doenças no filho pretendido. $\mathrm{O}$ estudo aconselhador é um processo de informação sobre as consequências e riscos de uma doença que pode ser transmitida hereditariamente, tendo como intuito evitá-la (CASABONA, 1999), sendo que pode ser realizado não somente antes da fecundação, mas nas fases sucessivas a ela.

Se for pré-conceptivo, pode-se optar por medidas anticonceptivas, como a não procriação com o uso de material genético próprio, a seleção do sexo do futuro filho para evitar a transmissão de algumas doenças (ORDÁS, 2002) ou o uso de material genético doado $^{2}$; se o teste genético ocorrer após a concepção (portanto, no embrião), também pode-se optar por implantá-los, mantendo-os congelados, ou automaticamente descartá-los ${ }^{3}$.

$\mathrm{Na}$ Espanha, o aconselhamento genético é um direito exercido pelo paciente localizado entre os direitos de informação sanitária, que incluem a perspectiva da reprodução humana assistida ou o exercício do direito do paciente de saber sobre sua condição genética (ABELLÁN, 2007, p.19-20). A lei de reprodução humana de 2006 recepciona o aconselhamento genético como parte do procedimento, incluindo os doadores de material germinativo.

A fertilização assistida pressupõe a posterior implantação do embrião concebido em laboratório no corpo da mulher precedida do diagnóstico genético pré-implantacional, exame capaz de identificar os embriões que não reuniram condições favoráveis para fins de reprodução (ausência de desenvolvimento normal, divisão celular inexpressiva, alteração

\footnotetext{
${ }^{2}$ A lei brasileira de número 11.105/2005, no seu artigo 25, não permitiu a engenharia genética em células humanas germinativas, o que inclui gametas e embriões.

${ }^{3}$ Não há vedação na Ordem jurídica brasileira sobre o descarte embrionário, restando inclusive previsto no art. $5^{\circ}$ da lei 11.105/2005 que os embriões não implantados, inviáveis e congelados há mais de três anos, podem ser doados para as pesquisas com células-tronco.
} 
genética ou cromossômica) (GEBER, 2004). Há de se registrar que é justamente o uso deste diagnóstico que motiva o surgimento de uma série de questões éticas importantes. A fertilização assistida, desenvolvida desde 1980 como uma técnica capaz de propiciar um filho a quem tenha uma impossibilidade de concebê-lo de maneira natural, acaba também se transformando num instrumento a serviço da neoeugenia, tendo em vista dois aspectos importantes: a seleção de embriões por meio do diagnóstico pré-implantatório e a seleção dos doadores de gametas quando pertinente (ADORNO, 1998, p.74-75).

A legitimidade do diagnóstico pré-implantacional, que tem como consequência a seleção e o descarte embrionários, vem sendo explicada pelo fato de ser o embrião "um ser humano numa fase muito precoce do seu desenvolvimento", sendo que, em determinadas situações, se argumenta que "outros valores se podem, eventualmente, sobrepor aos da vida humana incipiente (p.ex. o valor de uma vida familiar harmônica e equilibrada, que seria gravemente atingida pela sobrevida de uma criança com grave anomalia psíquica ou física)"(OSSWALD, 2005, p.22).

Assim, pode-se entender que o exame pré-implantatório embrionário tem se mostrado um dos passos necessários e indispensáveis à concretização do processo procriativo artificial, posto que a fertilização em laboratório não garante a obtenção, por si só, de embriões com condições de se desenvolverem no corpo humano. A medicina especializada tem associado o êxito dos procedimentos assistidos de reprodução ao preciso uso do diagnóstico.

No Brasil, a prática da engenharia genética em célula germinal humana, zigoto ou embrião humano, que pode ser destinada a fins eugênicos, foi proibida a partir da lei 11.105/2005. O inciso IV do art. $3^{\circ}$ da lei determina que engenharia genética é a "atividade de produção e manipulação de moléculas de ADN/ARN recombinante"(BRASIL, 2005), o que não esclarece o alcance exato da conduta vedada. Restou necessário esclarecer se a lei proíbe qualquer forma de manipulação genética, o pode incluir a terapia gênica. Há quem entenda que a vedação é apenas quanto às condutas que modifiquem a estrutura do DNA, excluindo do dispositivo a terapia gênica celular, que tem como proposta sanar enfermidades genéticas diagnosticadas.

Terapia gênica é "el tratamento de uma enfermedad através de la manipulación genética. Esto incluye, por ejemplo, el tratamiento del hipotiroidismo con hormonas tiroideas o el suministro de esteroides para reducir la inflamación en el asma". Ela traz como consequência "la inducción, represión, estimulación o inhibición de diferentes genes en 
distintos tejidos del organismo" (GONZALÉZ, 2008, p.145). Para outros, a terapia gênica pode agregar a possibilidade de promover alterações genéticas não terapêuticas, com o objetivo de melhorar a condição genética do futuro indivíduo, como no caso da inserção de um gene que melhore algum aspecto, como beleza, inteligência, ou, mesmo o prolongamento da vida, esta seria então chamada terapia gênica de melhoria (YUNTA, 2003, p.74).

Para Habermas, o diagnóstico pré-implantacional, devem ser considerado "por si só como moralmente admissível ou juridicamente aceitável se sua aplicação for limitada a poucos e bem definidos casos de doenças hereditárias graves que não poderiam ser suportadas pela própria pessoa potencialmente em questão". Posteriormente, essa permissão, por conta dos avanços, será estendida a intervenções em células somáticas e germinativas com vistas a prevenir doenças hereditárias ou semelhantes futuras. Assim, se conceberia a separação entre eugenia negativa, que tem motivação aparentemente justificada, já que tem função terapêutica, da eugenia positiva, que parece injustificada, por buscar o aperfeiçoamento e estar pautada em critérios de perfeição (HABERMAS, 2010, p.26).

Alguns parâmetros científicos são invocados para justificar a prática de condutas seletivas motivada por fundamentos terapêuticos.

Si la enfermedad está causada por genes autossômicos dominantes, lo
normal es tener un alelo dominante, no es normal ser homocigoto para esa
enfermedad. El carácter pasa directamente de indivíduos afectados a la
descendencia, basta que uno de los padres esté afectado para que los hijos
lo estén; el carácter está presente en todas las generaciones; cada
descendiente de un parental afectado tiene un $50 \%$ de posibilidades para
estar afectado; puede darse el caso de que dos individuos afectados tengan
un hijo que no lo esté, pero en un porcentaje muy bajo. El carácter o
enfermedad aparece en la descendencia de padres no afectados pero
portadores; la descendência de dos individuos afectados siempre lo estará;
si sólo es uno de los parentales el afectado, la descendência tendrá un $50 \%$
de estarlo; además, los indivíduos afectados generalmente pertenecen a
generaciones alternas (MUÑNOZ-NUÑEZ et al, 2005, p.344).

Em 2000, nos Estados Unidos, no Estado do Colorado, o casal Nash, com a ajuda da seleção genética de embriões, concebeu um filho para tentar salvar, com as células do cordão umbilical, a filha que era portadora da Anemia de Fanconi. No Reino Unido, em 2002, no caso Zain Hashmi, o casal tinha um filho de quatro anos com talassemia, que precisava de transplante de medula (ABELLÁN, 2006, p.21-22). Daí para cá, outras situações aconteceram de modo que a seleção genética passou a ser um recurso admissível e recomendado quando motivado pela possibilidade de salvar a vida de um terceiro.

$\mathrm{Na}$ contramão da desconfiança quanto às práticas demasiadamente seletivas, Arthur 
Caplan, Glenn McGee e David Magnus (1999, p.2), em artigo especializado sobre o assunto, entendem existir argumentos suficientes que justifiquem a prática da eugenia com fins de aperfeiçoamento.

No moral principle seems to provide sufficient reason to condemn individual eugenic goals. While force and coercion, compulsion and threat have no place in procreative choice, and while individual decisions can have negative collective consequences, it is not clear that it is any less ethical to allow parents to pick the eye colour of their child or to try and create a fetus with a propensity for mathematics than it is to permit them to teach their children the values of a particular religion, try to inculcate a love of sports by taking them to football games, or to require them to play the piano. In so far as coercion and force are absent and individual choice is allowed to hold sway, then presuming fairness in the access to the means of enhancing our offsprings' lives it is hard to see what exactly is wrong with parents choosing to use genetic knowledge to improve the health and wellbeing of their offspring ${ }^{4}$.

Para tal proposta, a escolha motivada por argumentos terapêutico ou por argumentos de aperfeiçoamento restaria portanto admitida, já que fruto de uma perspectiva consolidada no diário da vida cotidiana e na busca por uma vida melhor. A não incidência da imposição, da força ou do fundamento arbitrário e a manifestação clara do assentimento conferem a legitimação necessária às práticas eugênicas em geral segundo a análise defendida pelos autores $(1999$, p.2).

Acrescente-se que o diagnóstico pré-implantacional também pode propiciar a seleção de sexo do filho, que, na maioria dos países, incluindo o Brasil, é permitido se for para evitar a incidência de doenças determinadas. A escolha do sexo ocorrerá mediante a análise dos cromossomos que definem o sexo embrionário e é fulcrada na prevenção de enfermidades ligadas ao gênero. A escolha não pode ser com o objetivo de controlar o nascimento para fins de correção demográfica, por simples preferência dos pais, ou por impulso ideológico de que há um sexo superior ao outro (MORENO, 2012, p.15).

A seleção desenfreada de características humanas a partir de tais diagnósticos de intervenção esbarra na proteção constitucional à integridade, naturalidade e diversidade do

\footnotetext{
${ }^{4}$ Nenhum princípio moral parece dar razão suficiente para condenar metas eugênicas individuais. Enquanto força e coerção, compulsão e ameaça não têm lugar na escolha de procriação, e, enquanto as decisões individuais podem ter consequências negativas coletivas, não é claro que é menos ético permitir que pais escolham a cor dos olhos de seu filho ou queiram criar um feto com uma propensão para a matemática, do que permitir-lhes ensinar os valores de uma religião em particular as crianças, tente inculcar um amor de esportes, levando-os para jogos de futebol, ou para obrigá-los a tocar piano. Na medida em que a coerção e a força estão ausentes, a escolha individual é permitida a prevalecer, então, presumindo equidade no acesso aos meios de melhorar a vida dos filhotes, é difícil ver o que exatamente está errado com os pais que optem por usar o conhecimento genético para melhorar a saúde e o bem-estar de sua prole (Tradução livre). (CAPLAN; McGEE; MAGNUS, 1999, p.2).
} 
patrimônio genético, demandando o repensar de uma atuação desmedida. O patrimônio genético, enquanto bem jurídico fundamental, é destinado à atual e às futuras gerações, o, de pronto, evidencia a natureza de interesse coletivo.

\section{A AUTOCOMPREENSÃO DA ESPÉCIE DIANTE DAS PRÁTICAS EUGÊNICAS}

Algumas formas de intervenção no processo de constituição da existência do ser humano, como o recurso à fertilização assistida, já são nitidamente aceitas, o que faz com que se possa constatar que, aparentemente, do ponto de vista social, as decisões em torno da condição e da consequente proteção do embrião humano extracorpóreo já foram tomadas. A questão não é tão simples no âmbito de uma reflexão político-jurídica moralmente fundamentada (HABERMAS, 2010, p.25), pois, os fatos até então já constatados reforçam o temor social de que a dinâmica da Ciência, da biotecnologia, da medicina e da economia evidencie um desgovernado produzir de fatos consumados que não podem mais ser normativamente revisitados em prol do delineamento de uma nova e necessária conformação.

A ausente demarcação do limite conceitual entre a prevenção do nascimento de uma criança gravemente doente e o aperfeiçoamento do patrimônio hereditário, motivado por questões variadas, torna o juízo de permissibilidade sobre as práticas interventivas mais complexo e apresenta consequências. O crescimento da expectativa de intervir de forma corretiva no genoma humano para que as doenças genéticas sejam evitadas torna a ausente delimitação entre a prevenção e a conduta eugênica uma questão político-legislativa (HABERMAS, 2010, p.30), ou seja, que pode localizar-se num plano eminentemente prático e dispensar maiores reflexões.

Sobre o juízo de aperfeiçoamento ou melhora, a minusciosa pesquisa de Allen Buchanan (2009, p.350-351) aponta para a real necessidade de se ter pelo menos uma ideia aproximada do que seria a perspectiva de melhoria da espécie. É útil distinguir entre modos e tipos de aprimoramentos, pois, tais modos de melhorias incluem a engenharia genética em embriões e gametas humanos (inserção ou supressão de genes que ocorrem naturalmente; a inserção de cromossomos artificiais ou produtos de biologia sintética; a manipulação de funções reguladoras de genes); a engenharia farmacêutica (administração de medicamentos que afetam a mente ou o corpo); as interferências dos recursos da tecnologia da vida do homem; e o cultivo de órgãos e tecidos em laboratório (presumivelmente usando tecnologias 
de células-tronco). Os tipos incluem melhorias cognitivas, afetivas e motivacionais; o aumento da longevidade; a maior resistência e/ou imunidade completa a várias doenças ${ }^{5}$.

A percepção cultural a respeito da vida humana preliminar evidencia a aceitação social dos processos de manipulação biológica, ínsitos à era da biotecnologia. Ilustrativamente, tem-se o uso contínuo e natural dos recursos assistidos de reprodução e a possibilidade de realizar pesquisas científicas com embriões humanos, no Brasil chancelada pelo Supremo Tribunal Federal. Essa mudança na percepção cultural da sociedade que admite a habitualidade na intervenção da vida é o impulso para que os impactos decorrentes da avaliação do problema das condutas eugênicas sejam minimizados. A naturalização da aceitação da proposta genético-biotecnológica é também fruto do pragmatismo científico moderno, que promove o convencimento sutil diminuindo a relevância de certas reflexões.

O contexto atual caminha para a cada vez mais aceitação social da tecnização da medicina se ela estiver alicerçada no discurso de uma expectativa de vida mais longa e saudável, e assim "a ciência e a técnica estiveram até o momento informamelmente aliadas ao princípio liberal de que todos os cidadãos devem ter a mesma chance de moldar sua própria vida de maneira autônoma" (HABERMAS, 2010, p.35). O problema surge então quando se tenta "moralizar a natureza humana" por meio das intervenções legislativas. A proteção pelo Direito poderia encontrar expressão num "direito à uma herança genética em que não houve intervenção artificial"(HABERMAS, 2010, p.38), o que de pronto seria confrontado com a admissibilidade da eugenia negativa, justificada pela medicina.

Para Habermas, “o conhecimento de uma programação eugênica do próprio patrimônio hereditário limita a configuração autônoma da vida do indivíduo e mina as relações fundamentalmente simétricas entre pessoas livres e iguais" (HABERMAS, 2010, p.33). No mesmo percalço, o uso de novas tecnologias provoca estranhamentos nos modos de experiência e interiorização da pessoa em torno de si mesma. Pode-se pensar, então, numa correlação entre três acontecimentos: “consolidação das ciências e de um imaginário técnico-

\footnotetext{
5 Assim, conforme o original: "[...] it is necessary to have at least a rough idea of the prospects for enhancement. It is useful to distinguish between modes and types of enhancements. Modes of biomedical enhancement include the following: genetic engineering of human embryos and gametes (the insertion or deletion of naturally occurring genes, either from humans or from other species; the insertion of artificial chromosomes or products of synthetic biology; and the manipulation of gene regulatory functions); pharmaceutical enhancements (administration of drugs that affect the mind or the body); human-machine interfaces; and laboratory-grown organs and tissues (presumably using stem cell technologies and possibly even synthetic biology). Kinds of enhancements include improved cognitive, affective, and motivational capacities; increased longevity; and greater resistance and/or complete immunity to various diseases" (BUCHANAN, 2009, p.350-351).
} 
científico, sobretudo a partir dos avanços tecnológicos da revolução industrial”, o conhecido "modo de ser do homem e sua constituição como sujeito autônomo" e "a produção de uma experiência espaço-temporal que problematiza a relação do homem com o presente, concebendo o futuro como lugar das mudanças e da realização dos projetos" (TUCHERMAN, 2017, p.5).

O panorama descrito inaugura a perspectiva pós-humanista em que o ser humano passa a ser inserido e o cômodo e tradicional modo com que a pessoa se concebia enquanto parte de uma existência passa a sofrer significativa reificação.

A constituição do ser humano como sujeito autônomo também se transforma a partir do momento em que seja ela fruto da seletividade exarada pelo conhecimento aplicado através de uma programação genética. Passa-se a querer saber se a necessária proteção da integridade de patrimônios hereditários pode desqualificar a possibilidade de que os mesmos sejam manipulados, e, do ponto de vista individual, busca-se também saber se há um direito humano a uma herança genética não artificializada (HABERMAS, 2010, p.37-38).

O fato de que uma pessoa passe a ser a concretização das intenções de outra estabelece uma relação de assimetria entre o programado (ou o eugenizado) e o programador (o eugenista) (HABERMAS, 2010). A partir deste espectro, os pilares do liberalismo são corrompidos porque a liberdade de escolha de alguém subjugará a liberdade de existência do outro, cuja constituição é pré-determinada por uma programação emanada de uma vontade alheia.

A tentativa de "moralizar a natureza humana" pode corroborar a concepção da autotransformação genética da espécie como fomentadora do aumento da autonomia do indivíduo ou admiti-la como destruidora dessa capacidade autônoma à medida em que a concebe como fruto programado e a destititui da condição de acaso (HABERMAS, 2010, p.41). O ser humano, antes fruto do acaso genético, passa a ser a revelação de um projeto parental programado, articulado em prol de satisfazer a expectativa de alguém.

A necessidade de autocompreender-se sob uma nova perspectiva torna-se uma imanência advinda da sociedade técnica, biotecnologizada e pautada pelos caminhos do pragmatismo científico. Essa autocompreensão deve partir da busca de legitimidade, justificada pelo encontro de alguns argumentos. A conduta diagnóstica ou aconselhadora préconceptiva busca a efetivação do direito à saúde, manifestado pela possibilidade de poder decidir pela concepção de filhos saudáveis. O aconselhamento tem natureza omissiva, permite 
decidir pela procriação ou pela não procriação, considerando os resultados expostos pelo diagnóstico, logo, sua legitimidade tem cunho exclusivamente terapêutico. Se, de algum modo, o aconselhamento genético ou qualquer exame desta natureza for efetivado fora do âmago terapêutico, ou seja, com vistas às escolhas de padrões fenotípicos específicos, como cor de cabelo e olhos, intelecto e características físicas, os fundamentos que podem legitimálo não mais existirão, posto que desaparece o argumento do direito à saúde. A finalidade terapêutica é o único pressuposto admissível para concretização dos diagnósticos em embriões humanos. O diagnóstico tem função preditiva e visa a não implantação de um embrião com problemas de ordem biológica ou genética previamente diagnosticado.

O limite objetivo para tal perspectiva está na proteção ao patrimônio genético, flexibilizada quando motivada pela necessidade de intervenções justificadas pelo direito à saúde. Acrescente-se desde já, que há de se refletir, talvez numa outra pesquisa específica, como identificar de maneira pragmática quais doenças, por exemplo, podem propiciar o descarte embrionário, já que devem ser considerados fatores como o grau de comprometimento da saúde e/ou o tempo de sobrevida. O desafio é evidente e não pode ser superado sem a contribuição técnica da medicina.

A experiência moral humana, traduzida pela autocompreensão em torno da existência da própria espécie, foi atingida quando não mais se consegue identificar o limite entre o exercício da liberdade, através de contratos que agreguem possibilidades neoeugênicas, e o que deve permanecer indisponível, a partir das motivações jurídico-filosóficas construídas aos longo dos tempos. Essa nova compreensão em torno de si mesmo demanda da pessoa humana as decisões a respeito de como as intervenções na constituição da vida preliminar da espécie devem ser admitidas.

\section{CONSIDERAÇÕES FINAIS}

O futuro da natureza humana, redimensionado e modificado pela própria espécie, caminha para o necessário esclarecimento quanto à legitimação das intervenções genéticas na vida em sua forma preliminar. Isto naturalmente demanda a categorização dessas condutas, que devem ser analisadas distintamente, posto estarem motivadas por propostas distanciadas.

A existência de uma necessidade terapêutica, portanto pautada na condução de um protocolo de tratamento com vistas a afastar, minimizar ou curar a doença, pressupõe uma análise de natureza médica e não deve ser confundida com projetos reprodutivos motivados 
pela idealização de um padrão fenotípico perfeito.

O que se consubstancia como uma conduta eugênica, hoje, reflete considerável mudança de significado em relação à compreensão desta em outro momento da história. É possível perceber um caminho natural, no comportamento social, que pugna pela desvinculação do conceito de eugenia ao conceito de seleção, a fim de expurgar a carga negativa que o primeiro agrega, isto porque a aceitação social de algumas práticas seletivas novas tem como principal fator de contribuição o acesso ao conhecimento científico.

A eugenia liberal é dividida em uma prática seletiva com base nas escolhas de características supérfluas, como cor de cabelo, olhos, peso e outras questões (chamada de eugenia positiva) e outra prática conduzida pelo objetivo de garantir a saúde e a qualidade de vida da futura pessoa, ou seja, de ter filhos saudáveis (chamada de eugenia negativa), esta capaz de fundamentar-se como forma de concretização do direito à saúde.

A saída é compreender que os diagnósticos embrionários devam ser realizados com justificativa apenas de ordem terapêutica, afastando-se toda finalidade de cunho "aperfeiçoador" ou "melhorador". Como os limites entre a terapia e o aperfeiçoamento não são facilmente identificados, resguarda-se à atividade técnica especializada a necessidade de indicação das enfermidades genéticas graves que justificam o descarte embrionário quando diagnosticada a patologia. Não se pode pensar que todas as doenças de ordem genética podem restar catalogadas, pois, envolvem coeficientes variáveis, como aspectos multifatoriais ou de aparição tardia. A avaliação das situações em específico há de ser sempre considerada já que podem agregar variáveis a serem ponderadas.

A reflexão adequada sobre a nova forma de autocompreensão da própria espécie leva em consideração a necessidade de proteger o patrimônio genético numa medida justa e adequada, considerando a simbologia do argumento da alteridade que propicia o redimensionamento das consequências das condutas que aparentam estar apenas relacionadas ao espectro da individualidade. A questão exorbita o fundamento da autonomia para resvalar em conteúdo de natureza coletiva, tendo em vista tratar-se também da necessidade de conservar a existência plúrima da espécie, através de sua constituição genética natural. 


\section{REFERÊNCIAS}

ABELLÁN, Fernando. Selección genética de embriones. Entre la libertad reproductiva y la eugenesia. Granada: Comares, 2007.

ADORNO, Roberto. Bioética y Dignidad de la persona. Versión española del propio autor. Madrid: Tecnos, 1998.

BECK, Ulrich. La sociedad del riesgo: Hacia una nueva modernidad. Barcelona: Paidós, 1998.

BRASIL. Lei 11.105/2005. Disponível em: <www.planalto. gov.br/lei/L11105>. Acesso em: 07 jan. 2017.

BUCHANAN, Allen. Moral Status and HumanEnhancement. Philosophy \& Public Affairs, 2009.

CAPLAN, Arthur; McGEE, Glenn; MAGNUS, David. What is immoral about eugenics? Center of Bioethics Papers. University of Pensilvania. v.319. November, 1999. Disponível em: < ibrary.upenn.edu/1017/1008>. Acesso em: 07 jan. 2017.

CASABONA, Carlos Maria Romeo. Do gene ao direito. São Paulo: IBCCrim, 1999.

Las prácticas eugenésicas: nuevas perspectivas. In: CASABONA, Carlos Maria Romeo. La eugenesia hoy. Bilbao-Granada: Editorial Comares, 1999.

EMALDI CIRIÓN, Aitziber. El consejo genético y sus implicaciones jurídicas. BilbaoGranada: Comares, 2001.

GEBER, Selmo. Implicações éticas do diagnóstico pré-implantacional. In: CASABONA, Carlos Maria Romeo; QUEIROZ, Juliane Fernandes (Coords.). Biotecnologia e suas implicações ético-jurídicas. Belo Horizonte: Del Rey, 2004.

GONZÁLEZ, Sonia Sánchez. Proyecto genoma humano visto desde el pensamiento de la complejidad. implicaciones bioéticas. Acta Bioethica, 2008, v.14.

HABERMAS, Jürgen. O futuro da natureza humana. A caminho de uma eugenia liberal? Tradução de Karina Janini. São Paulo: Martins Fontes, 2010.

MEIRELLES, Ana Thereza. Neoeugenia e reprodução humana artificial. Limites éticos e jurídicos. Salvador: Editora Juspodivm, 2014.

MORENO, Claudia Lucía Albujar. El Diagnóstico Genético Preimplantatorio y sus Implicancias Ético-Jurídicas como Mecanismo de Selección y Discriminación de la Vida del Concebido obtenido mediante Fecundación In Vitro. Revista de Investigación Jurídica, Chiclayo, n. 4, 2012, ano 2.

MUÑOZ-NUÑEZ M.; et al. Enfermedades hereditarias y técnicas de detección preimplantacionales. Revista Iberoamericana de Fertlidad, v.22, n.5, set.-out., 2005. 
ORDÁS, Maria Cristina Hidalgo. Análisis jurídico-científico Del concebido artificialmente. Em el marco de la experimentación gênica. Barcelona: Editorial Bosch, 2002.

OSSWALD, Walter. Diagnóstico genético e medicina predizente. Diagnóstico prénatal. In: ASCENSÃO, José de Oliveira (Coord.). Estudos de Direito da Bioética. Coimbra: Almedina, 2005.

TUCHERMAN, Ieda. O pós-humano e sua narrativa. Disponível em: <www.pos.eco.ufrj.br/ docentes/prof_itucherman.html>. Acesso em: 07 jan. 2017.

YUNTA, Eduardo Rodríguez. Terapia génica y princípios éticos. Acta Bioethica, 2003, ano IX, n.1. 